\title{
High performance thin film organic lasers for sensing applications
}

\section{Láseres de alta eficiencia basados en películas orgánicas delgadas: aplicaciones como sensores}

\author{
Marta Morales-Vidal1,2,S* \\ 1. Departamento Física Aplicada and I. U. de Materiales, Universidad de Alicante, Apartado de correos \\ 99, Alicante E-03080, Spain \\ 2. Present address: I.U. Física Aplicada a las Ciencias y las Tecnologías Universidad de Alicante, \\ Apartado de correos 99, Alicante E-03080, Spain \\ ${ }^{*}$ E-mail: marta.morales@ua.es \\ S: SEDOPTICA member
}

Received: 18/05/2019 Accepted: 21/08/2019

DOI: $10.7149 /$ OPA.52.3.51023

\begin{abstract}
:
This paper summarizes the most important results of the PhD Thesis presented by M. M-V. and directed by M.A. Díaz-García. Thin film organic lasers have demonstrated its applicability at laboratory scale, spectroscopy, optical communications, chemical sensing or biosensing. To bring optically-pumped solution processed thin film organic lasers to the real market the active material must be: able to emit at low pump excitation (low threshold), photostable to ensure a long operational lifetime; capable of emitting at various wavelengths or colours, processable by low-cost solution-based methods and mechanically flexible. We show all these properties amalgamated in a novel organic active materials: carbon-bridged oligo( $p$-phenylenevinylene)s (COPVn) dispersed in thermoplastic polymer films and a COPV-polymer prepared as a neat film. Novel devices by using different architectures have been optimized and studied. The high performance achieved with these laser devices has been demonstrated by pumping them with an inexpensive laser diode. The sensing applicability of thin film organic lasers has been also demonstrated by preparing and characterizing bulk refractive index sensors and biosensors.
\end{abstract}

Key words: distributed feedback, polymeric resonator, photostability, label-free sensors, ErbB2 biomarker.

\section{RESUMEN:}

Este documento resume los resultados más importantes de la tesis doctoral presentada por M. M-V. y dirigida por M.A. Díaz-García. Los láseres orgánicos de película delgada se aplican a escala de laboratorio, espectroscopía, comunicaciones ópticas, detección química o biodetección. Para conseguir llevar este tipo de láseres de manera eficiente al mercado, el material activo ha de cumplir las siguientes características: capacidad de emitir al ser bombeando a baja energía, alta fotoestabilidad para garantizar una larga vida útil; capacidad de emitir a diferentes longitudes de onda o colores, procesabilidad por métodos de bajo coste y que el dispositivo sea mecánicamente flexible. Todas estas propiedades están presentes en un novedoso material orgánico activo basado en oligómeros con puente de carbono (COPVn) disperso en películas de polímero termoplástico. Se han optimizado y estudiado nuevos dispositivos mediante el uso de diferentes geometrías y resonadores, observando un alto rendimiento y logrando bombearlos con un simple diodo láser. Algunas aplicaciones de detección con estos dispositivos han sido demostradas: sensores de índice de refracción y biosensores.

Palabras clave: retroalimentación distribuida, resonador polimérico, fotoestabilidad, sensores sin marcadores, biomarcador ErbB2. 


\section{REFERENCES AND LINKS / REFERENCIAS Y ENLACES}

[1] F. P. Schäfer, W. Schmidt, J. Volze, “Organic dye solution laser,” Appl. Phys. Lett. 9, 306 (1966).

[2] X. Liu, P. Stefanou, B. Wang, T. Woggon, T. Mappes, U. Lemmer, "Organic semiconductor distributed feedback (DFB) laser as excitation source in Raman spectroscopy,” Opt. Express 21, no. 23, 2894128947 (2013).

[3] a) C. Grivas, M. Pollnau, “Organic solid-state integrated amplifiers and lasers," Laser Photonics Rev. 6, no. 4, 419-462 (2012).

b) C. Grivas, "Optically pumped planar waveguide lasers: Part II: Gain media, laser systems, and applications," Prog. Quantum Electron., 45-46, 3-160 (2016).

[4] J. Clark, G. Lanzani, "Organic photonics for communications," Nat. Photonics 4, no. 7, 438-446 (2010).

[5] Y. Wang, P. O. Morawska, A. L. Kanibolotsky, P. J. Skabara, G. A. Turnbull, I. D. W. Samuel, "LED pumped polymer laser sensor for explosives," Laser Photonics Rev. 7, no. 6, 71-76 (2013).

[6] E. Heydari, J. Buller, E. Wischerhoff, A. Laschewsky, S. Döring, J. Stumpe, "Label-free biosensor based on an all-polymer DFB laser," Adv. Opt. Mater. 2, no. 2, 137-141 (2014).

[7] M. Morales-Vidal, P. G. Boj, J. A. Quintana, J. M Villalvilla, A. Retolaza, S. Merino, María A. Díaz García, "Distributed feedback lasers based on perylenediimide dyes for label-free refractive index sensing," Sens. Actuators B-Chem. 220, 1368 - 1375 (2015).

[8] A. Retolaza, J. Martínez-Perdiguero, S. Merino, M. Morales-Vidal, P. G. Boj, J. A. Quintana, J. M Villalvilla, M. A. Díaz García, "Organic distributed feedback laser for label-free biosensing of ErbB2 protein biomarker," Sens. Actuators B-Chem. 223, 261 - 265 (2016). DOI: 10.1016/j.snb.2015.09.093

[9] P. G. Boj, M. Morales-Vidal, J. M Villalvilla, J. A. Quintana, J. A. Quintana, A. Marcilla, M. A. Díaz García. "Organic distributed feedback laser to monitor solvent extraction upon thermal annealing in solution-processed polymer films," Sens. Actuators B-Chem. 232, 605 - 610 (2016).

[10] S. Chénais, S. Forget, "Recent advances in solid-state organic lasers," Polym. Int. 61, no. 3, 390-406 (2012).

[11] M. Morales-Vidal, P. G. Boj, J. M. Villalvilla, J. a. Quintana, Q. Yan, N.-T. Lin, X. Zhu, N. Ruangsupapichat, J. Casado, H. Tsuji, E. Nakamura, M. A. Díaz-García, “Carbon-bridged oligo( $p$-phenylenevinylene)s for photostable and broadly tunable, solution-processable thin film organic lasers," Nat. Commun. 6, 8458 (2015).

[12] M. Morales-Vidal, J. A. Quintana, J. M Villalvilla, P. G. Boj, H. Nishioka, H. Tsuji, E. Nakamura, G. L. Whithworth, G. A. Turnbull, I. D. W. Samuel, M. A. Díaz-García, "Carbon-bridged ( $p$ phenylenevinylene) polymer for low-threshold solution-processed distributed feedback lasers," Adv. Opt. Mat. 6, 13 (2018).

[13] J. A. Quintana, J. M Villalvilla, M. Morales-Vidal, P. G. Boj, X. Zhu, N. Ruangsupapichat; H. Tsuji, E. Nakamura, M. A. Díaz García, "An efficient and color-tunable solution-processed organic thin-film laser with a polymeric top-layer resonator," Adv. Opt. Mat. 5, 1 - 9 (2017).

[14] E. M. Calzado, A. Retolaza, S. Merino, M. Morales-Vidal, P. G. Boj, J. A. Quintana, J. M Villalvilla, María A. Díaz García. "Two-dimensional distributed feedback lasers with thermally-nanoimprinted perylenediimide-containing films," Opt. Mat. Express. 7 - 4, 1295 - 1301 (2017).

[15] I. D. W. Samuel, G. A Turnbull, “Organic semiconductor lasers,” Chem. Rev. 107, no. 4, 1272-1295 (2007).

[16] M. D. McGehee, A. J. Heeger, "Semiconducting (conjugated) polymers as materials for solid-state lasers," Adv. Mater. 12, no. 22, 1655-1668 (2000).

[17] V. Trabadelo, A. Juarros, A. Retolaza, S. Merino, M. G. Ramírez, V. Navarro-Fuster, J. M. Villalvilla, P. G. Boj, J. A. Quintana, M. A. Díaz-García, "Highly photostable solid-state organic distributed feedback laser fabricated via thermal nanoimprint lithography," Microelectron. Eng. 87, no. 5-8, 1428-1430 (2010).

[18] E. R. Martins, Y. Wang, A. L. Kanibolotsky, P. J. Skabara, G. A. Turnbull, I. D. W. Samuel, "LowThreshold Nanoimprinted Lasers Using Substructured Gratings for Control of Distributed Feedback," Adv. Opt. Mater. 1, no. 8, 563-566 (2013).

[19] X. Zhu, H. Tsuji, J. Casado, E. Nakamura, “Carbon-Bridged Oligo(phenylenevinylene)s: Stable $\pi$-Systems with High Responsiveness to Doping and Excitation," J. Am. Chem. Soc. 134, 19254 (2012).

[20] M. A. Díaz-García, E. M. Calzado, J. M. Villalvilla, P. G. Boj, J. A. Quintana, F. Giacalone, J. L. Segura, N. Martín, "Concentration dependence of amplified spontaneous emission in two oligo-(pphenylenevinylene) derivatives,” J. Appl. Phys., 97, no. 6, 63522 (2005). 
[21] E. M. Calzado, J. M. Villalvilla, P. G. Boj, J. A. Quintana, R. Gómez, J. L. Segura, M. A. D. García, “Amplified spontaneous emission in polymer films doped with a perylenediimide derivative," Appl. Opt. 46, 3836-3842, (2007).

[22] R. Xia, W. Y. Lai, P. A. Levermore, W. Huang, D. D. C. Bradley, "Low-threshold distributed-feedback lasers based on pyrene-cored starburst molecules with 1,3,6,8attached oligo(9,9-Dialkylfluorene) arms," Adv. Funct. Mater. 19, no. 17, 2844-2850 (2009).

[23] M. G. Ramirez, M. Morales-Vidal, V. Navarro-Fuster, P. G. Boj, J. A. Quintana, J. M Villalvilla, A. Retolaza, S. Merino, M. A. Díaz García. "Improved performance of perylenediimide-based lasers," J. Mat. Chem. C. 1 - 6, 1182 - 1191 (2013).

[24] M. G. Ramírez, S. Pla, P. G. Boj, J. M. Villalvilla, J. A. Quintana, M. A. Díaz-García, F. Fernández-Lázaro, Á. Sastre-Santos, "1,7-Bay-substituted perylenediimide derivative with outstanding laser performance," Adv. Opt. Mater. 1, no. 12, 933-938 (2013).

[25] Y. Tan, C. Ge, A. Chu, M. Lu, W. Goldshlag, C. S. Huang, A. Pokhriyal, S. George, B. T. Cunningham, "Plastic-based distributed feedback laser biosensors in microplate format," IEEE Sens. J. 12, 1174 (2012).

[26] M. Lu, S.S. Choi, U. Irfan, B. T. Cunningham, “Plastic distributed feedback laser biosensor,” Appl. Phys. Lett. 93, 111113 (2008).

[27] Y. Tan, A Chu, M. Lu, B. T. Cunningham, "Distributed Feedback Laser Biosensor Noise Reduction,” IEEE Sens. J. 13, no. 5, 1972-1978 (2013).

[28] A. M. Haughey, B. Guilhabert, A. L. Kanibolotsky, P. J. Skabara, M. D. Dawson, G. a Burley, N. Laurand, "An oligofluorene truxene based distributed feedback laser for biosensing applications," Biosens. Bioelectron. 54, 679-86 (2014).

\section{Introduction}

Since the first practical laser, demonstrated by Maiman in 1960, applications using lasers have spread among many areas, such as: research, medicine, telecommunications, material processing, etc. Nowadays, lasers are even used in our everyday life, for example they are frequently used in compact disc (CD) and digital video disc (DVD) players, printers and supermarket scanners. Among a wide variety of available lasers, those in which the active medium is organic are particularly interesting because thanks to the broad photoluminescence (PL) spectra of organic molecules, they allow tuning the emission wavelength across the whole visible spectrum. Besides, thanks to the chemical versatility offered by chemical synthesis, the material properties can be easily modified. The first organic laser was a liquid dye laser [1], in which the active medium consisted of an organic molecule (a dye) dissolved in a solvent. Liquid dyelasers are commercially available many years ago (they are used, for example, in medicine to remove skin vascular lesions). However, these devices present some limitations: large size, the need of high-power pumping sources, difficulties in handling due to the need of recirculating the liquid solution to prevent dye photodegradation, as well as, PL quenching due to molecular interaction. So, researchers have pursued for years the development of compact and easy-to-handle organic solid-state lasers (OSLs). Among them, thin film organic lasers (TFOLs), those in which the active material is in the form of a thin waveguide film of good optical quality (low propagation losses), have special importance towards achieving compactness, mechanical flexibility and easy integration with other devices. Within this subclass, those in which the active film can be prepared by means of solution-based methods, such as spin-coating, printing, etc., are preferred for their prospect of reducing device cost.

A distributed feedback (DFB) laser, consisting of a solution-processable waveguide including a diffractive relief grating, has been a particularly successful TFOL which has already demonstrated its applicability, at laboratory scale, as tunable source for spectroscopy [2], amplifiers for optical communications [3, 4], vapor explosive chemical sensors [5] and highly sensitive and possibly specific non-intrusive label-free sensors for drug discovery, biological research, diagnostic tests, food safety, etc. [6, 7, 8, 9]. Today, one of the major challenges remaining to bring TFOLs to the real market is to find efficient, photostable, tunable and chemical versatile active material. Aiming to develop efficient, integrable, solution-processable, mechanical flexible, and low production cost device architectures.

Two important classes of organic gain media investigated in the literature for TFOLs are:

-Conjugated polymers which are a subset of semiconducting polymers. They are organic macromolecules that are characterized by a backbone chain of alternating double and single bonds. Their overlapping $p$ - 
orbitals create a system of delocalised $\pi$-electrons, which can result in interesting and useful optical and electronic properties, for example poly( $p$-phenylene vinylene) (PPV) or poly(9,9'-dioctylfluorene) (PF0).

-Aromatic dyes diluted in a matrix such as rhodamine (Rh) perylenediimides (PDIs), 4(dicyanomethylene)-2-methyl-6-(4-dimethylaminostyryl)-4H-pyran (DCM) or pyrromethene 567 (PM567) diluted in a matrix such as thermoplastic polymer.

However, organic gain materials typically used in thin film organic lasers do not fullfill the different requirements at the same time. Conjugated polymers generally show low threshold but generally poor photostability while dyes show better photostability and higher threshold $[3,10]$. In this context, the main objective of this thesis was to prepare high performance TFOLs and to demonstrate their capability for sensing. We show a novel class of active compounds called carbon-bridged oligo $(p$ phenylenevinylene)s (COPVs), COPVn $(n=1-6)$, which are hybrids of conjugated polymers and smallmolecules laser dyes, ideal for use in organic semiconductor lasers [11]. In addition, we study a novel active polymer, called poly-COPV1, based on the basic unit of COPV1, prepared as high-quality neat films [12]. The excellent properties of these materials in addition to their appropriate device design [13], allow to overcome the trade-off between the device performance and durability and thanks to their chemical versatility they can emit as long as the whole visible spectrum. We also demonstrated three different sensing applications of an optically-pumped DFBs, whose principle of operation consists in detecting changes in the emission laser wavelength [7, 8, 9]. Here, it has been described two of them: 1) bulk refractive index sensors able to detect the refractive index of different liquids deposited on the top of the devices, 2) biosensors able to detect the concentration of the cancerous protein ErbB2 in a serum sample deposited on the top of the device.

\section{Fundamental photophysics}

A parameter typically used in the literature to assess the potential of a given material for laser applications is the amplified spontaneous emission (ASE). ASE is not a true lasing, but a mixture of spontaneous emission and stimulated emission. In these systems gain is so high that amplification is obtained in a single pass through the active material without the need of a laser cavity. There are some differences between ASE and laser emission: coherence and directionality are less developed in ASE emission than in laser emission. The ASE bandwidth spectrum is narrower than the corresponding fluorescence bandwidth but broader than the laser emission linewidth. In ASE there are not resonant laser modes, since there is no cavity. The typical configuration of ASE is a waveguide. To achieve waveguiding two conditions need to be fulfilled: 1) The refractive index of the active film should be larger than that of the substrate and the cover; 2) in asymmetric waveguides in which the refractive index of the substrate and the cover are different, the active film thickness should be larger than a certain value, called the cutoff thickness for the propagation of one mode.

In DFBs light is waveguided through large distances in the gain medium, due to the periodic modulation of the refractive index incorporated in the resonator. In a 1D DFB laser, light is reflected by Bragg scattering following the Bragg equation (1).

$$
m \cdot \lambda_{\text {Bragg }}=2 \cdot n_{\text {eff }} \cdot \Lambda
$$

Where $m$ is the order of diffraction, $n_{\text {eff }}$ is the effective refractive index of the waveguide, and $\Lambda$ is the grating period. In second order $(m=2)$ DFB laser, light is coupled out of the film by first order diffraction, in a direction perpendicular to the waveguide film a wavelength $\lambda_{\mathrm{DFB}}$ close to $\lambda_{\mathrm{Bragg}}$ (given by eq. 1 ). One advantage of using 1D gratings operating in the second order of diffraction, $m=2$ is that the emitted wavelength occurs in a perpendicular direction, independently of their excitation angle over the sample. It is easy to tune the emission wavelength in these devices by changing the grating period $(\Lambda)$ or the effective refractive index ( $n_{\text {eff }}$ ). The effective refractive index depends on the film thickness $(h \mathrm{f})$, as well as the refractive indices of the substrate, film and cover $\left(n_{\mathrm{s}}, n_{\mathrm{f}}, n_{\mathrm{c}}\right)$. Each guided-mode corresponds to a singular effective refractive index which is a solution of the wave equation. Another particular 1D resonator consists in a sub-structured grating with an additional ridge in the unit cell that separate feedback along the waveguide and it allows a laser threshold decrement [12]. In addition, there are other kinds of resonators that are frequently used in organic lasers [14, 15, 16]: 2D DFBs (diffractive resonators that may apply a 2D feedback in the plane of the active film), micro-ring resonators (light is emitted in all radial directions) or planar microcavities. 


\section{Experimental methods}

\section{3.a. Thin film preparation}

The preparation of laser devices starts dissolving the polymer to be used as a matrix, polystyrene (PS), and a small amount of organic molecule with laser activity (COPV or PDI-0) in a volatile solvent (toluene). We have also dissolved poly-COPV1 polymer $(n=1.68$, at $\lambda=527 \mathrm{~nm})$ in toluene. In the last case, PS matrix is not needed. The solution is spin-coated over a transparent substrate without grating (fused silica or BK-7 glass) or over a grating. Finally, some thermal treatments at $90{ }^{\circ} \mathrm{C}$ are performed because although most of the solvent evaporates during the last step of spin-coating, there is still some remaining solvent [9].

\section{3.b. Distributed feedback laser resonators}

Throughout the thesis, we prepared devices by different techniques and with different DFB geometries. In Fig. 1 we show three of the DFB geometries studied.

In the geometry Type 1 (RBelNs), Fig. 1a, the second order grating is engraved on inorganic substrate by thermal nanoimprint lithography (thermal-NIL). The substrate and the resist are heated up and the stamp is pressed into the resist. After cooling down and demolding, two plasma etchings were performed to transfer the pattern to the substrate. The resonators were provided by the technological centre Tekniker $[7,17]$.

In the geometry Type 2 (RTopNs), Fig. 1b, the second order grating is written on a photoresist layer deposited over the active film by holographic lithography (HL). Resonators by HL have been fabricated in our lab at the University of Alicante [13]. In this case, the grating is recorded by the interference of two beams. The light intensity pattern between exposed and unexposed areas is translated in hardness variations over water-soluble dichromated gelatine (DCG). After desensitizing in a cool water bath, a relief grating is obtained by dry development in an oxygen plasma [13].

In the geometry Type 3 (RBels), Fig. 1c, the sub-structured grating is imprinted on a resist layer previously deposited onto glass substrates and the active films are spin-coated onto the UV-NIL gratings. They consist of two ridges of width $w$, displaced by a distance $x$, within each second order unit cell, and with a periodicity $\Lambda[12,18]$. These resonators were prepared during a predoctoral stay at the University of St Andrews.

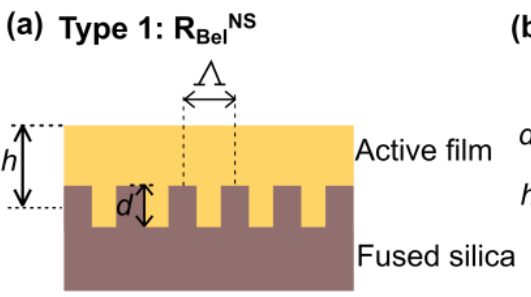

(b) Type 2: $\mathbf{R}_{\text {Top }}{ }^{\mathrm{NS}}$

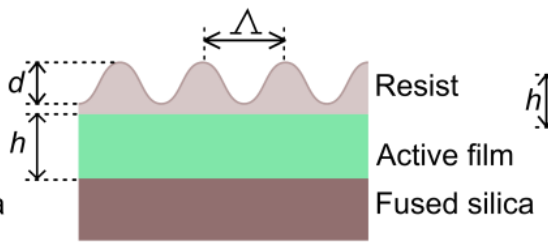

(c) Type 3: $R_{\text {Bel }}$ s

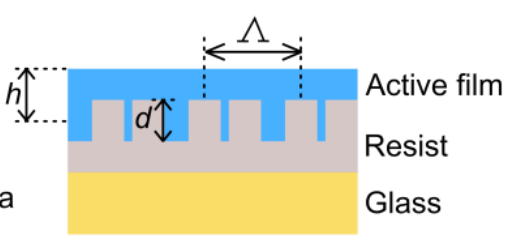

Fig.1. (a) Geometry Type 1 (RBelNs): active film over a second order (not sub-structured) grating engraved on inorganic substrate. (b) Geometry Type 2 (RTopNs): second order grating (not sub-structured) engraved on a photoresist layer. The grating is over the active film deposited on a fused silica substrate. (c) Geometry Type 3 (RBels): sub-structured grating imprinted in a resist previously deposited onto glass substrates; the grating is below the active film.

\section{3.c. Optical characterization}

The setup used to characterize the ASE properties of active films deposited over substrates without grating consists of an optical excitation source which allows pumping with a stripe $(3 \mathrm{~mm} \times 0.5 \mathrm{~mm})$ perpendicular to the device surface and collecting the emitted light by the edge of the sample. We have used: a Nd-YAG laser (10 Hz, $10 \mathrm{~ns}$ ) emitting at $355 \mathrm{~nm}$ (to pump COPV1 and COPV2) or $532 \mathrm{~nm}$ and a NdYAG laser with a Raman cell emitting at $436 \mathrm{~nm}$, an OPO laser emitting at $450 \mathrm{~nm}$ (4 ns pulse width; $20 \mathrm{~Hz}$ repetition rate) and a $445 \mathrm{~nm}$ GaN laser diode (20 ns, $20 \mathrm{~Hz}$ ). The ASE threshold is the pump intensity at which the PL emission spectrum starts narrowing. To obtain net gain ( $\left.g_{\text {net }}\right)$ the intensity of the spectrum is fitted as a function of the pump stripe length, for a given pump intensity. The photostability is determined as the time (or number of pump pulses) at which the ASE intensity decays to half of its initial value. 
The setup used to DFB characterization only differs in the following points: the cylindrical lens is replaced by a spherical one to obtain a spot (diameter $=1.1 \mathrm{~mm}$ ) instead a stripe; the angle of incidence is around $20^{\circ}$ and the emitted light is collected perpendicular to the film surface; the photostability is obtained as in ASE, although now we use the DFB spectra. The DFB threshold is obtained identifying the intensity at which a drastic change of slope in the output intensity curve occurs; the linewidth of DFB emission is smaller than in ASE, typically minor than $1 \mathrm{~nm}$ due to their higher coherence [11-12]. The setup used to characterize DFB sensors is very similar to the previously described one, but now the excitation and light emission collection is done through the transparent substrate, and the sample is placed horizontally to the optical table to deposit liquid superstrates or biomolecules [7-8].

\section{High performance compounds as novel laser materials}

\section{4.a. Carbon-bridged oligo( $p$-phenylenevinylene)s (COPVn)}

At present, a major challenge is to find a material which shows simultaneously low threshold, long photostability and wide tunability, as well as the capability of being processed from solution-based methods. Fortunately, we have found that these properties are amalgamated in a novel family of compounds (COPVs) $[11,19]$. The optical properties of films consisting of PS as passive matrix in which oligomers with increasing number of monomer units are dispersed, COPVn $(1-6)$ (Fig. 2, Table 1), have been studied (all the COPV compounds were synthesized by the group of Prof. Nakamura at the University of Tokyo). The remarkable properties of COPV compounds are: robust all-carbon skeleton, substituents attached to the bridging carbons, flat and rigid $\pi$-system. These properties allow to obtain: high photoluminescence quantum yield (PLQY) over the whole range of visible spectrum, high stability against light irradiation, low energy thresholds, miscibility and dispersibility in different matrices and solubility in different solvents.
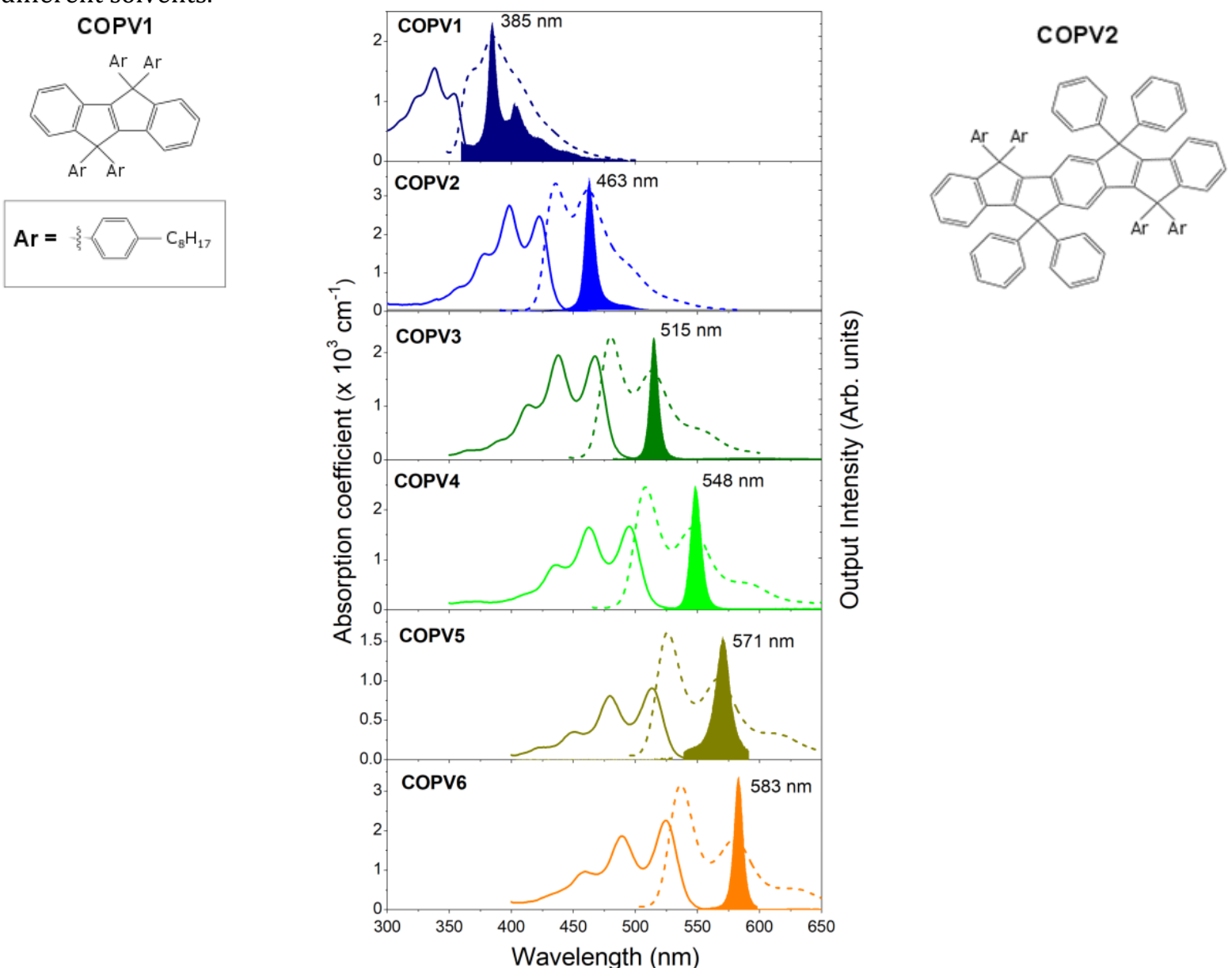

Wavelength $(\mathrm{nm})$

Fig. 2. Chemical structures of COPV $n(n=1$ and 2). Absorption coefficient, $\alpha$ (solid line, left axis), photoluminescence intensity

(dashed line, right axis) and amplified spontaneous emission, ASE, intensity (filled area, right axis), versus wavelength, $\lambda$, for polystyrene films doped with COPV1-6 (3 wt $\%, 3 \mathrm{wt} \%, 2 \mathrm{wt} \%, 1.7 \mathrm{wt} \%, 1 \mathrm{wt} \%$ and $2 \mathrm{wt} \%$, respectively) over fused silica substrates. The ASE wavelength value for each compound is indicated in its corresponding figure. 
The conjugation length of the investigated COPV oligomers (COPV $n$, with $n=1-6$ ) shows the possibility of emission wavelength tuning by means of scalable chemical synthesis. Unlike aromatic dyes, they allow to systematically tune the emission laser wavelength over a wide range of the visible spectrum. The net gain coefficient (gain minus losses), at two different pump intensities, for $8 \mathrm{wt} \%$ COPV6 doped PS film, have been: $g_{\text {net }}=60 \mathrm{~cm}-1$ at $43.3 \mathrm{~kW} \mathrm{~cm}-2$ and $g_{\text {net }}=6.3 \mathrm{~cm}-1$ at $11.5 \mathrm{~kW} \mathrm{~cm}-2$. The obtained values are much higher than those obtained with other $p$-phenylenevinylene oligomers $\left(g_{\text {net }}=13 \mathrm{~cm}-1\right.$ at $I_{\text {pump }}=55 \mathrm{~kW} \mathrm{cm-2)} \mathrm{[20]} \mathrm{and} \mathrm{PDIs}$ dispersed in PS: $\left(g_{\text {net }}=8 \mathrm{~cm}-1\right.$ at $\left.I_{\text {pump }}=60 \mathrm{~kW} \mathrm{cm-2}\right)$ [21] and only about twice lower than state-of-the-art organic semiconductors [22].

It is remarkable the very low DFB threshold obtained with $8 \mathrm{wt} \%$ COPV6 film: $0.7 \mathrm{~kW} \mathrm{~cm}-2$. This threshold is very close to the requirements of LED pumping. Furthermore, most of the films based on the different COPV oligomers have exceptional photostability, particularly the DFB based on a PS film containing $2 \mathrm{wt} \%$ of COPV6 shows the longer lifetime 106 pump pulses, pumping two times above their threshold. This photostability is in stark contrast to that of flexible counterparts of COPVs such as phenylenevinylene oligomers [20] and polymers whose ASE under ambient conditions lasts for just a few minutes [3,10]. This result is even better than devices based on perylenediimide that has 105 pump pulses $[23,24]$.

\section{4.b. Optical performance of poly-COPV1 neat films}

The optical performance of a neat film of poly-COPV1 was explored during a short stay in St Andrews University [13]. Since in this case the compound is not diluted in a matrix, the film absorbance is significantly higher, more than one order of magnitude higher than that obtained with films based on COPVn dispersed in PS, besides, its processing is simpler. The ASE performance of the poly-COPV1 film is much better than the COPV1 based film dispersed in polystyrene, obtaining an ASE threshold 30-times lower and an ASE lifetime 300-times longer. The significant enhanced photostability is due to the polymerization strategy used (lower number of reactive sites). The DFB devices with geometry Type 2 and 3 have the active material and resonator made of polymeric material, which means that it will be able to give rise to flexible devices. Thresholds as low as $0.7 \mathrm{kWcm}-2$, under pumping with an inexpensive GaN laser diode and operational lifetimes of $1 \times 106$ pump pulses were obtained for a device with geometry Type 3 (sub-structured parameters: $w=95 \mathrm{~nm}, x=75 \mathrm{~nm}$ ).

TABLE 1. Geometrical and operational parameters of ASE and DFB lasers based on Figure 1.

\begin{tabular}{|c|c|c|c|c|c|c|c|c|c|}
\hline $\begin{array}{l}\text { Active } \\
\text { material }\end{array}$ & $\begin{array}{l}\text { wt\% } \\
\text { in PS }\end{array}$ & $\begin{array}{l}\text { Geometry } \\
\text { Type\# }\end{array}$ & $\begin{array}{l}\Lambda \# \# \\
(\mathrm{~nm})\end{array}$ & $\begin{array}{l}h^{*} \\
(\mathrm{~nm})\end{array}$ & $\begin{array}{l}\lambda_{\text {pump** }} \\
(\mathrm{nm})\end{array}$ & $\begin{array}{l}\alpha\left[\lambda_{\text {pump }}\right] \S \\
(\mathrm{cm}-1)\end{array}$ & $\begin{array}{l}\lambda_{\mathrm{ASE} \S} \\
(\mathrm{nm})\end{array}$ & $\begin{array}{l}\lambda \mathrm{DFB} \dagger \\
(\mathrm{nm})\end{array}$ & $\begin{array}{l}\text { Ith-DFB †† } \\
(\mathrm{kW} \mathrm{cm-2)}\end{array}$ \\
\hline COPV1 & 3.0 & ASE & - & 610 & 355 & $1.13 \times 10_{3}$ & 384.5 & - & - \\
\hline COPV2 & 3.0 & ASE & - & 610 & 355 & $6.0 \times 10_{2}$ & 462.7 & - & - \\
\hline COPV3 & 2.0 & 1 & 321 & 650 & 436 & $1.91 \times 10_{3}$ & 514.8 & 516.4 & 1.0 \\
\hline \multirow[t]{2}{*}{ COPV4 } & 1.7 & ASE & - & 540 & 436 & $0.90 \times 10_{3}$ & 548.2 & - & - \\
\hline & 5.0 & 1 & 353 & 600 & 436 & $2.4 \times 10_{3}$ & 549.2 & 556.6 & 1.0 \\
\hline COPV5 & 1.0 & 1 & 368 & 630 & 532 & $1 \times 10_{2}$ & 571.1 & 573.1 & 20 \\
\hline \multirow[t]{2}{*}{ COPV6 } & 2.0 & 1 & 380 & 470 & 532 & $1.6 \times 10_{3}$ & 583.4 & 579.6 & 2.1 \\
\hline & 8.0 & 1 & 380 & 490 & 532 & $6.5 \times 10_{3}$ & 584.4 & 586.6 & 0.7 \\
\hline \multirow{2}{*}{$\begin{array}{l}\text { Poly- } \\
\text { CoPV1 }\end{array}$} & - & 2 & 331 & 405 & 450 & $6.67 \times 10_{4}$ & 528.6 & 531.9 & 1.9 \\
\hline & - & 3 & 350 & 140 & 445 & $6.67 \times 10_{4}$ & 527.3 & 534.9 & 0.7 \\
\hline
\end{tabular}

\#Geometry type as a function of fig. 1 (1, 2 or 3), and thin film over fused silica substrate (ASE). \#\#Grating period (error is $\pm 1 \mathrm{~nm}$ ). *Active film thickness (error is $\pm 1 \mathrm{~nm}$ ). ${ }^{* *}$ Pump wavelength. $\S$ Absorption coefficient. $\S \S A S E$ wavelength (error is $\pm 0.1 \mathrm{~nm}$ ). ${ }_{+} \mathrm{DFB}$ wavelength (error is $\pm 0.1 \mathrm{~nm}$ ). ${ }_{+} \mathrm{DFB}$ threshold. Error $\sim 10 \%$. 


\section{Distributed feedback lasers for sensing applications}

\section{5.a. Bulk refractive index sensor}

The basic principle of DFB sensors is to use an electromagnetic field to detect changes in the refractive index on the waveguide that are translated to a change in wavelength. In DFB bulk refractive index sensors, $\lambda_{\mathrm{DFB}}$ changes are due to changes in the refractive index of the cover layer (liquid superstrate deposited on top). For example, we have used: distilled water, aqueous solutions of glycerine and pure glycerine. The sensing performance is typically characterized by the bulk sensitivity, $S b$, defined as the resonance wavelength change per refractive index unit (expressed in $\mathrm{nm} / \mathrm{RIU}$ ).

$$
S b=\frac{d(\Delta \lambda)}{d n}
$$

The sensor resolution, $r$, which refers to the minimum wavelength shift that can be measured, is also an important parameter. In comparison to other refractive index sensors, organic DFB lasers are very attractive because of their high $S b$ and $r$ [7,25], simple fabrication and integration with other devices, wavelength tuning capability and small size. Although it has been demonstrated different bulk refractive index sensors, until now, it has not been used with a material which shows simultaneously high photostability and a relatively low threshold as the one we have used: PDI-O [23]. A very thin film $\left(h_{\mathrm{f}}=\right.$ $160 \mathrm{~nm}$ ) device (Fig. 3 a) has shown a sensitivity value ( $S b=32 \mathrm{~nm} / \mathrm{RIU})$ comparable to other single-layer DFB sensors reported in the literature which demonstrated capability to detect biomolecules (25), while its threshold is relatively high $\left(\right.$ IthDFB $\left.=210 \mathrm{~kW} / \mathrm{cm}_{2}\right)$ and its operational durability moderate $\left(\tau_{1 / 2} \sim 10_{4}\right.$ pp). A slight increase of thickness $(h \mathrm{f}=180 \mathrm{~nm})$ has allowed decreasing the threshold by three times, while its sensitivity diminishes only slightly $(S b=28 \mathrm{~nm} / \mathrm{RIU})$.

\section{5.b. DFB laser as biosensor}

In DFB biosensors the analyte detection is produced by observing changes in DFB wavelength due to specific capture of biomolecules at the surface. In this case the evanescent wave can detect nanoscale materials by functionalizing the surface of the active film and by detecting small changes on the laser wavelength emitted. The advantage to avoid sensor labels (designed to be measured by its colour or its ability to generate photons at one wavelength) is that we can use simpler and cheaper materials and detection setups. There are few reports of organic DFB lasers used as biosensing devices, most of them performed by Cunningham and studying proteins: human immunoglobulin G protein [26], tumour necrosis alpha [25], rabbit immunoglobulin G protein [27], avidin-biotin protein [28]. In these studies sensitivities of around $20 \mathrm{~nm} / \mathrm{RIU}$ have been enough to detect biomolecules. ErbB2 protein overexpression ( $>15 \mathrm{ng} / \mathrm{mL}$ ) is one of the most widely investigated clinical indicators of: breast, ovarian, gastrointestinal, lung cancers. Until now, some methods are stablished for the assessment of this protein, but never by using a DFB sensor. A single-layer DFB with a thin active film $(h \mathrm{f}=160 \mathrm{~nm})$, as explained before, has been used to detect the ErbB2 cancer biomarker (Fig. 3). In the Fig. 3b we represent DFB spectra of the sensor device in each step of the immunoassay.

(a)

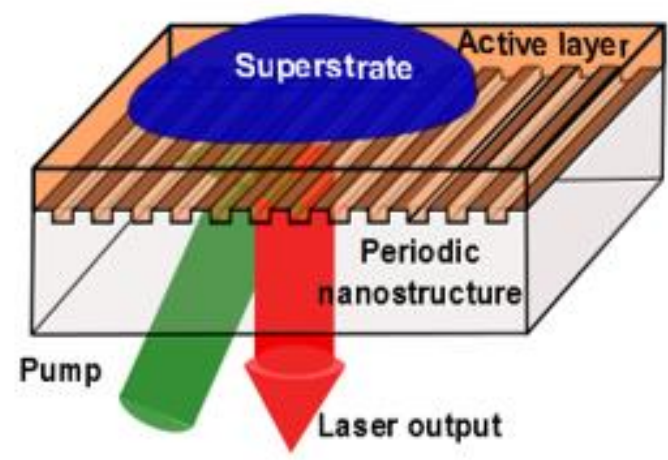

(b)

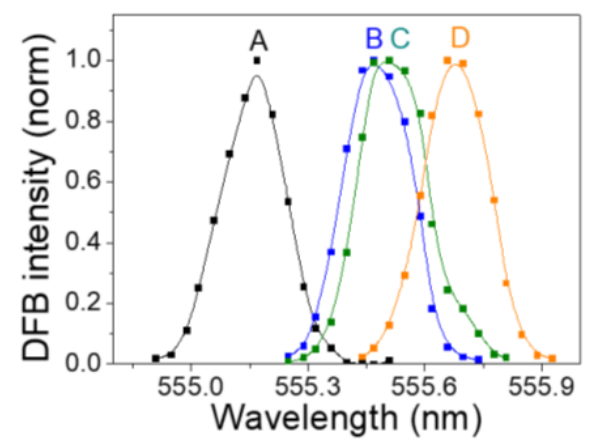

Fig. 3. (a) Scheme of DFB sensor, including excitation and collection geometry. (b) From left to right: A: Before functionalization ( $\lambda$ DFB $=555.2 \mathrm{~nm}$ ). B: After functionalization with receptor layer (antiErbB2). C: After BSA blocking surface. D: After analyte addition (ErbB2) at a concentration of $10 \mathrm{ng} / \mathrm{ml}$. 
The most important steps to biosensor functionalization have been: a) Biofunctionalization overnight of the surface with anti-ErbB2 monoclonal antibodies (this is the receptor layer); b) incubation a bovine serum albumin (BSA), the blocking surface to minimize potential non-specific binding (for 2 hours); c) then, the ErbB2 protein biomarker is incubated (for 2 hours). The limit of detection obtained, LOD $=14$ $\mathrm{ng} / \mathrm{mL}$, (concentration 3 times the standard deviation of the negative samples), is the lowest for a DFB based protein biosensor. And this limit of detection is lower than the established clinical cut-off for the ErbB2 biomarker.

\section{Conclusions}

We have demonstrated that COPV-based DFB lasers have optimal properties for laser action [11], they satisfy simultaneously the different requirements needed for applications: wide wavelength tunability across the visible spectrum (380-590 nm), long operational lifetimes ( 106 pump pulses), low threshold $\left(0.7 \mathrm{~kW} / \mathrm{cm}_{2}\right)$, processability by solution-based methods and low cost. We have also demonstrated that a COPV-based polymer, poly-COPV1, has great potential as active material for thin film organic lasers [12]. This material can be prepared as a high-quality neat waveguide film without any host matrix. Therefore, it has the advantages of higher pump absorption and simpler processing compared with previously described oligomeric COPV derivatives, which require mixing with another material such as a thermoplastic polymer to obtain a good quality film with good laser performance. Thresholds as low as 0.7 $\mathrm{kW} \mathrm{cm}-2$ allow to pump with an inexpensive GaN laser diode emitting at $445 \mathrm{~nm}$. Operational lifetimes as high as 106 pump pulses were obtained although, in this case, the active material was not dispersed on a matrix. The already excellent DFB performance of the devices prepared in this work could be further improved by optimizing the grating, the excitation wavelength or the polymer matrix (in the case of COPVn based devices). The novel method used in this thesis to prepare DFB gratings, by HL, on organic layers placed on top of the active films allows varying easily the grating period [13]. The excitation wavelength used in this work could be further improved by choosing a pumping wavelength closer to the maximum absorption, and therefore, to achieve lower thresholds. New polymer matrices could reduce waveguide losses.

Furthermore, we have explored the sensing applicability of DFBs [7, 8, 9]. The feasibility of organic DFB laser sensors consisting of active films of PS doped with the PDI-O laser dye as bulk refractive index sensors has been investigated through the changes observed in their laser emission wavelength upon exposure to different liquid superstrates. Even more important, we have also demonstrated their sensor capability of detecting a cancer biomarker (ErbB2). The sensor specificity and its limit of detection for ErbB2 protein opens the possibility to use organic DFB lasers for clinical applications. The use of new COPV derivatives instead of PDIs as active materials might lead to a great advance towards their commercialization. On the one hand, these devices show low thresholds and the possibility of pumping with compact sources. On the other hand, a blue-shifted emission (achieved with COPV $n$ with $n<3$ ) would make possible to increase their sensitivity, and finally, its high photostability could improve the sensor durability.

\section{Acknowledgements}

The PhD thesis described in this paper, has been supported by the Spanish Government, through projects: MAT2008-06648-C02-01 and MAT-2011-28167-C02-01, and FPI grant (BES-2009-020747). MMV also acknowledges support from the European Community (FEDER) and Junta de Castilla y León (JCYL) through Postdoctoral Fellowship (no. SA046U16), as well as, under a Postdoctoral project CDEIGENT/2018/024 (Generalitat Valenciana, Spain). The scientific contribution of María A. Díaz-García, Pedro Boj, José A. Quintana and José M. Villalvilla at the University of Alicante and the different collaborations with Tekniker technological centre and the Universities of Málaga, Tokyo and St Andrews are also acknowledged. 